\title{
ANÁLISE COMPARATIVA ENTRE OS INSTDA PATENTE DE INVENÇÃO E DE MODELO DE UTILIDADE E FORMAS DE PROTEÇÃO CORRELATADAS: DESENHO INDUSTRIAL, PROTEÇÃO DE NOVAS CULTIVARES E TOPOGRAFIA DE CIRCUITOS INTEGRADOS
}

DOI: http://dx.doi.org/10.18616/pidi18

Larissa Pierozan - UFRGS

E-mail: larissa.pierozan@gmail.com Kelly Lissandra Bruch - UFRGS 


\section{INTRODUÇÃO}

O principal objetivo deste capítulo diz respeito a distinguir as diversas formas de proteção e compará-las com a patente de invenção. O trabalho pretende ser um guia básico de algumas figuras da propriedade intelectual voltado, principalmente, para estudantes e interessados na área.

A propriedade intelectual é uma área de estudo que tem ganhado maior importância no direito brasileiro. No Brasil, ganhou maior destaque após o país tornar-se signatário do TRIPS (Agreement on Trade-Related Aspects of Intellectual Property Rights) ${ }^{38}$ e criar legislações visando estar em conformidade com o previsto no referido tratado. Assim, publicou-se a Lei no 9.279, de 14 de maio de 1996 (BRASIL, 1996), referente, principalmente, às patentes e aos desenhos industriais; a Lei no 9.456, de 25 de abril de 1997 (BRASIL, 1997a), de cultivares; e a Lei no 11.484 , de 31 de maio de 2007, relativa às topografias de circuitos integrados. Também houve a publicação da Lei no 9.610, de 14 de fevereiro de 1998, que versa sobre os direitos autorais, e da Lei 9.609, de 19 de fevereiro de 1998, relacionada aos programas de computador, as quais, no entanto, não serão abordadas neste capítulo, visto que o principal destaque foi para as patentes e a criação dos desenhos industrias que, na lei anterior de 1967, figuravam como patentes de desenho industrial. Destarte, com a separação do desenho industrial das patentes de invenção, bem como com a criação de um direito sui generis para a proteção de plantas, e, posteriormente, de uma lei para topografias de circuitos integrados, os objetos de suas proteções, seus direitos e afins confundem-se e generalizam-se entre si. Dessa forma, pretende-se comparar essas figuras de proteção para definir cada uma. Cuide-se que não é um objetivo aprofundar-se em cada forma protetiva, mas sim em suas diferenças e similitudes. Usar-se-á o método comparativo e de análise das leis nos 9.279/96, no 9.456/97 e no 11.484/07, atualmente vigentes no Brasil.

$\mathrm{O}$ ordenamento jurídico brasileiro não se faz claro quanto à possibilidade de dupla proteção de uma inovação por meio dos institutos da Propriedade Industrial. Dessa forma, o trabalho também se propõe a examinar a viabilidade de tutelar, simultaneamente, uma criação por duas formas de proteção de ativos intangíveis.

\footnotetext{
${ }^{38}$ Acordo sobre os Aspectos dos Direitos de Propriedade Intelectual Relacionados ao Comércio.
} 


\title{
PATENTE
}

A patente consiste em um certificado emitido pelo Instituto Nacional de Propriedade Industrial, que confere ao titular o direito de uso exclusivo de sua invenção e/ou de seu objeto de modelo de utilidade. A carta patente, em outras palavras, trata-se de um registro de título de propriedade temporária outorgado pelo Estado para os autores ou para outras pessoas, tanto físicas quanto jurídicas, que detenham os direitos sobre a criação.

O objetivo de conferir um tempo de uso exclusivo é que com uma invenção protegida que não pode ser explorada de forma econômica e livre por todos, haverá novas criações para concorrer com as primeiras. Para ser possível a concessão da patente, é preciso descrever o projeto de forma precisa e detalhada, assim essa descrição será publicada e disponível para consulta de quem tiver interesse. Dessa forma, há uma troca: o inventor disponibiliza a sua criação de forma detalhada e, se for o titular, ganha a propriedade e o direito de uso exclusivo por um determinado tempo de sua invenção. Simplificando o conceito, o INPI (2017, n.p.) define a patente como:

\begin{abstract}
Patente é um título de propriedade temporária sobre uma invenção ou modelo de utilidade, outorgado pelo Estado aos inventores ou autores ou outras pessoas físicas ou jurídicas detentoras de direitos sobre a criação. Em contrapartida, o inventor se obriga a revelar detalhadamente todo o conteúdo técnico da matéria protegida pela patente.
\end{abstract}

A patente pode ser subdivida em duas categorias: as patentes de invenção e as de modelo de utilidade. A primeira se refere à proteção de novas criações, enquanto a outra se refere à tutela de melhorias ou às mudanças em objetos já existentes. Um exemplo didático é a tesoura. Para proteger uma tesoura como nova criação, seria possível solicitar uma patente de invenção. Depois de protegida, seria possível desenvolver uma tesoura para canhotos, que teria uma melhoria funcional no uso da criação, podendo ser protegida por meio de uma patente de modelo de utilidade..$^{39}$

Para ser patenteada, a invenção deve atender a três requisitos: novidade, atividade inventiva e aplicação industrial. Tratando-se de modelo de utili-

\footnotetext{
${ }^{39}$ Artigo 9o da Lei 9.279/96.
} 
dade, o invento deve possuir: objeto de uso prático (ou parte deste), apresentar nova forma ou disposição e resultar em melhoria funcional no seu uso ou em sua fabricação. ${ }^{40}$

A proteção conferida pela Carta Patente refere-se ao teor das reivindicações, que devem ser interpretadas com base no relatório descritivo e nos desenhos. De tal modo, deve-se descrever clara e suficientemente, ou seja, de forma precisa, o objeto, de modo a possibilitar sua realização por técnico no assunto e indicar, quando for o caso, a melhor forma de execução. ${ }^{41}$

O pedido da patente de invenção deve se referir a uma única invenção ou a um grupo de invenções inter-relacionadas de maneira a compreenderem um único conceito inventivo. $O$ pedido de patente para modelos de utilidade referem-se a um único modelo principal, podendo incluir uma pluralidade de elementos distintos, adicionais ou variantes construtivas ou configurativas. ${ }^{42}$

O pedido de patente deve conter requerimento, relatório descritivo, reivindicações, desenhos - se necessário -, resumo e comprovante do pagamento da retribuição relativa ao depósito. O pedido será submetido a exame formal e, posteriormente, protocolizado. $O$ pedido de patente fica em sigilo por um período de 18 (dezoito) meses, período que pode ser antecipado a requerimento do depositante. ${ }^{43}$

A concessão da carta patente necessita de um exame de mérito - exame técnico quanto à possibilidade de patentear a criação, o qual ocorre na forma de relatório de busca -, de um parecer relativo à patenteabilidade do pedido, adaptação do pedido à natureza reivindicada, reformulação do pedido ou divisão, ou exigências técnicas. ${ }^{44}$ Além disso, o exame de mérito analisa se os requisitos de patenteabilidade estão presentes, de forma a não ser só uma mera confirmação da não existência de uma criação anterior similar.

Para ser passível de proteção por meio de patentes, a criação deve atender aos requisitos já mencionados e que constam nos artigos 8 e 9 da Lei no 9.279/96. No entanto, não se pode tutelar por meio de patente o que consta no artigo 18으 da Lei 9.279/96, pois são objetos considerados contrários à moral, aos bons costumes e à segurança, à ordem e à saúde pública. Também

\footnotetext{
${ }^{40}$ Artigo 9o da Lei 9.279/96.

${ }^{41}$ Artigo 24 da Lei 9.279/96.

${ }^{42}$ Artigo 23 da Lei 9.279/96.

${ }^{43}$ Artigo 30 da Lei 9.279/96.

${ }^{44}$ Artigo 35 da Lei 9.279/96.
} 
não se pode patentear o que não é considerado invenção (artigo 10 으 da Lei no 9.279/96), como as substâncias, as matérias, as misturas, os elementos ou produtos de qualquer espécie; o todo ou parte dos seres vivos, exceto os micro-organismos transgênicos que atendam aos três requisitos de patenteabilidade - novidade, atividade inventiva e aplicação industrial - previstos no artigo 8o e que não sejam mera descoberta.

O período de proteção conferido à patente de invenção é de 20 (vinte) anos da data do depósito ou o mínimo de duração da proteção de 10 (dez) anos após a concessão. Para os modelos de utilidade, confere-se a tutela por 15 (quinze) anos da data do depósito ou o mínimo de 7 (sete) anos após a concessão. Há a previsão de um tempo mínimo de proteção em razão do exame de mérito que, muitas vezes, pode levar anos para ser feito e, assim, haver a concessão da carta patente. A patente não pode ter sua proteção prorrogada.

O titular da patente tem o direito de impedir terceiro, sem o seu consentimento, de produzir, usar, colocar à venda, vender ou importar com esses propósitos produto objeto de patente e processo ou produto obtido diretamente por processo patenteado, além de poder obter indenização pela exploração indevida de seu objeto. ${ }^{45}$ Entretanto, o titular da patente possui seus direitos restringidos ${ }^{46}$ em relação aos atos de caráter privado e sem finalidade comercial, ou com finalidade experimental e para a preparação de medicamento de acordo com a prescrição médica para casos individuais, bem como para a produção de informações, de dados e resultados de testes relacionados à invenção patenteada, visando à obtenção do registro de comercialização, no Brasil ou em outro país, para a exploração e a comercialização do produto objeto da patente, após a expiração dos prazos estipulados no artigo 40.

Ademais, possuem limites legais ao direito do titular os produtos fabricados de acordo com a patente de processo ou de produtos colocados no mercado pelo titular ou com o seu consentimento.

A patente trata-se de uma forma de proteção de ativos intangíveis relacionada à invenção de um processo ou produto, bem como pode se referir à melhora na sua utilização ou fabricação. Deve-se discriminar todo o objeto da invenção na patente, de forma que ela possa ser reproduzida por técnicos na área. Conclui-se que as patentes se referem à função do objeto protegido, uma

\footnotetext{
${ }^{45}$ Artigos 42 e 44 da Lei 9.279/96.

${ }^{46}$ Artigo 43 da Lei 9.279/96.
} 
vez que no pedido, bem como no que é passível de tutela, requer-se não que se siga a forma da invenção ou do modelo de utilidade, mas para que e como se pode utilizá-los.

\section{DESENHO INDUSTRIAL}

O desenho industrial, também conhecido como design, trata-se de uma criação que é tanto ornamental quanto tem aplicação industrial. Ou seja, não pode ser uma simples obra de arte ou somente ter aplicação industrial. 0 desenho industrial reúne a técnica com a estética, é uma obra de arte aplicada que pode ser um tipo de fabricação industrial. ${ }^{47} \mathrm{O}$ que confere a proteção e o direito de propriedade é o registro de desenho industrial, documento conferido pelo Instituto Nacional de Propriedade Industrial - INPI. ${ }^{48}$

A Lei da Propriedade Industrial (Lei $n^{\circ}$ 9.279/96) define o que é desenho industrial no seu artigo 95:

Art. 95. Considera-se desenho industrial a forma plástica ornamental de um objeto ou o conjunto ornamental de linhas e cores que possa ser aplicado a um produto, proporcionando resultado visual novo e original na sua configuração externa e que possa servir de tipo de fabricação industrial. (BRASIL, 1996, n.p.).

Assim, depreende-se que é necessário o requisito da novidade e da originalidade. A caracterização de novidade está descrita no artigo 96 da Lei $n^{\circ}$ 9.279/96 como aquilo que não está no estado de técnica, ou seja, aquilo que não é de conhecimento público, novo no sentido de sua aplicação. O conceito de original, tratado no artigo 97 da Lei $n^{\circ}$ 9.279/96, faz referência ao objeto ser distinto dos demais, mesmo que possua elementos conhecidos, sem ser uma mera cópia ou imitação. Ainda, o artigo 98 da Lei n $9.279 / 96$ aborda o cunho artístico do desenho industrial: "Art. 98. Não se considera desenho industrial qualquer obra de caráter puramente artístico." (BRASIL, 1996, n.p.).

\footnotetext{
${ }^{47}$ PLETSCH, Laura Wolf. Desenho Industrial: Possibilidade de Dupla Proteção. Porto Alegre: PUCRS, 2009, p. 2.

${ }^{48}$ Artigo 94 da Lei 9.279/96.
} 
O registro protege o que é elencado no artigo 95, ou seja, a configuração externa do objeto. ${ }^{49}$ Para adquirir o registro da obra, faz-se necessária uma troca, a discrição detalhada no projeto e a publicação deste pelo direito de uso exclusivo por um tempo determinado. A publicização deverá representar clara e suficientemente o objeto e suas variações, se houver, sendo possível sua reprodução por técnico no assunto.

O pedido do registro deve tratar somente de um objeto, contudo são permitidas até vinte variações que se destinem ao mesmo propósito e guardem entre si a mesma característica distintiva preponderante..$^{50}$ Deve conter no pedido o requerimento, um relatório descritivo - se necessário -, reivindicações - se forem o caso -, desenhos ou fotografias, campo de aplicação do objeto e o comprovante do pagamento da retribuição relativa ao depósito. A lei coloca como exigência que os documentos do registro estejam em vernáculo nacional, a língua portuguesa. Os artigos 101 e 102 demonstram o protocolo do pedido:

Art. 102. Apresentado o pedido, será ele submetido a exame formal preliminar e, se devidamente instruído, será protocolizado, considerada a data do depósito a da sua apresentação.

Art. 103. O pedido que não atender formalmente ao disposto no art. 101, mas que contiver dados suficientes relativos ao depositante, ao desenho industrial e ao autor, poderá ser entregue, mediante recibo datado, ao INPI, que estabelecerá as exigências a serem cumpridas, em 5 (cinco) dias, sob pena de ser considerado inexistente.

Parágrafo único. Cumpridas as exigências, o depósito será considerado como efetuado na data da apresentação do pedido. (BRASIL, 1996, n.p.).

Após o depósito do pedido do registro de desenho industrial, seguindo as condições já mencionadas, ele será automaticamente publicado e simultaneamente concedido e expedido o seu registro. O pedido não possui sigilo, a não ser que seja requerido no prazo de 90 (noventa) dias, contados da data do

\footnotetext{
${ }^{49}$ A patente de modelo de utilidade protege o funcionamento do objeto, da criação, não sua forma externa.

${ }^{50}$ Artigo 104 da Lei 9.279/96.
} 
depósito, possuindo duração de 180 (cento e oitenta) dias, também contados a partir da data do depósito. ${ }^{51}$

Diferente da patente, para a concessão do registro de desenho industrial, não é necessário o exame de mérito. Esse exame, todavia, pode ser requerido pelo titular do desenho a qualquer tempo de vigência, sendo que o exame diz respeito aos aspectos de novidade e originalidade. A inexistência do exame obrigatório tem como objetivo a celeridade da concessão do registro, visto que se o pedido atender aos requisitos formais da lei, ele será concedido. Apesar de não ser obrigatória, a avaliação do mérito do objeto é de grande importância para conferir maior proteção ao titular do registro, principalmente em casos de ação judicial.

Falou-se sobre a definição de desenho industrial, sobre o pedido e o depósito, mas ainda não se mencionou o que é passível de registro. A Seção III do Capítulo II do Título II dos Desenhos Industriais da Lei 9.279/96 possui um único artigo sobre o que não é registrável. Isto é, primeiramente, o que for contrário à moral e aos bons costumes ou que ofenda a honra ou a imagem de pessoas, ou atente contra a liberdade de consciência, a crença, o culto religioso ou a ideia e os sentimentos dignos de respeito e veneração, um critério mais subjetivo. Também diz que não se enquadra a forma necessária comum ou vulgar do objeto, ou aquela determinada essencialmente por considerações técnicas ou funcionais, um critério mais objetivo. ${ }^{52}$ Além disso, faz-se referência ao já mencionado artigo 98 da Lei 9.279/96, o qual diz que não é desenho industrial, logo não é registrável, o que tenha caráter puramente artístico.

O período de proteção conferido pelo registro aos desenhos industriais é de 10 (dez) anos contados a partir da data do depósito. Diferentemente da patente, esse tempo pode ser prorrogado mais três vezes, com duração de cinco anos cada, assim resultando em um total de 25 (vinte e cinco) anos de vigência do registro. A ampliação do período de proteção é um atrativo, além da maior rapidez de registrar, para a escolha dessa forma de proteção. ${ }^{53}$

$O$ registro confere ao titular o direito de propriedade do desenho industrial, além de poder impedir terceiro, sem o seu consentimento, de produzir,

\footnotetext{
${ }^{51}$ Artigo 106. Depositado o pedido de registro de desenho industrial e observado o disposto nos arts. 100, 101 e 104, será automaticamente publicado e simultaneamente concedido o registro, expedindo-se o respectivo certificado.

${ }^{52}$ Artigo 100, inciso II, da Lei 9.279/96.

${ }^{53}$ Artigo 108 da Lei 9.279/96.
} 
usar, colocar à venda, vender ou importar com esses propósitos produto objeto de patente e processo ou produto obtido diretamente por processo protegido, bem como de obter indenização pela exploração indevida de seu objeto. O Título V da Lei da Propriedade Industrial, ${ }^{54}$ no Capítulo II, trata dos crimes, especificamente sobre os desenhos industriais. ${ }^{55}$

Há limites legais para os direitos conferidos ao titular do registro, pois apesar de ele poder impedir certas ações e até ter condutas criminalizadas pela lei, alguns atos podem ser praticados. São eles: os de caráter privado e sem finalidade comercial; os com finalidade experimental; a produção de informações e o produto colocado no mercado pelo titular ou com o seu consentimento. ${ }^{56}$

Um dos objetivos do desenho industrial seria conferir um design diferente e mais atraente para o consumidor, que possa influenciá-lo a adquirir o produto.

\section{PROTEÇÃO DE NOVAS CULTIVARES}

A proteção de novas cultivares protege uma nova cultivar e está regulamentada na Lei n 9.456/97, conhecida como Lei de Proteção de Cultivares. Em primeiro lugar, deve-se definir o que é uma cultivar e uma nova cultivar. A lei traz o conceito em seu artigo 3 o, incisos IV e V:

IV - cultivar: a variedade de qualquer gênero ou espécie vegetal superior que seja claramente distinguível de outras cultivares

\footnotetext{
${ }^{54}$ Art. 187. Fabricar, sem autorização do titular, produto que incorpore desenho industrial registrado, ou imitação substancial que possa induzir em erro ou confusão. Pena - detenção, de 3 (três) meses a 1 (um) ano, ou multa.

Art. 188. Comete crime contra registro de desenho industrial quem I - exporta, vende, expõe ou oferece à venda, tem em estoque, oculta ou recebe, para utilização com fins econômicos, objeto que incorpore ilicitamente desenho industrial registrado, ou imitação substancial que possa induzir em erro ou confusão; ou II - importa produto que incorpore desenho industrial registrado no País, ou imitação substancial que possa induzir em erro ou confusão, para os fins previstos no inciso anterior, e que não tenha sido colocado no mercado externo diretamente pelo titular ou com seu consentimento. Pena - detenção, de 1 (um) a 3 (três) meses, ou multa.

${ }_{55}$ O Código Penal (Decreto-Lei $n^{\circ} 2.848$, de 7 de dezembro de 1940) já tratava sobre os crimes da Propriedade Intelectual no Capítulo I do Título III dos crimes contra a propriedade imaterial, mas os artigos referentes ao desenho industrial foram revogados pela Lei 9.279.

${ }^{56}$ Artigo 109 da Lei 9.279/96.
} 
conhecidas por margem mínima de descritores, por sua denominação própria, que seja homogênea e estável quanto aos descritores através de gerações sucessivas e seja de espécie passível de uso pelo complexo agroflorestal, descrita em publicação especializada disponível e acessível ao público, bem como a linhagem componente de híbridos;

V - nova cultivar: a cultivar que não tenha sido oferecida à venda no Brasil há mais de doze meses em relação à data do pedido de proteção e que, observado o prazo de comercialização no Brasil, não tenha sido oferecida à venda em outros países, com o consentimento do obtentor, há mais de seis anos para espécies de árvores e videiras e há mais de quatro anos para as demais espécies. (BRASIL, 1997, n.p.).

Por essa definição, compreende-se que a proteção é sobre espécies vegetais novas, distinguíveis, homogêneas e estáveis, passíveis de uso pelo complexo agroflorestal e que tenham denominação própria. A proteção confere direitos ao seu titular, tais como as outras formas de proteção de ativos intangíveis. ${ }^{57} \mathrm{O}$ pedido da proteção de novas cultivares é feito no Serviço Nacional de Proteção de Cultivares (SNPC), órgão vinculado ao Ministério da Agricultura, Pecuária e Abastecimento - MAPA. O MAPA também oferece o registro de cultivares no Registro Nacional de Cultivares (RNC), cujo objetivo é permitir a comercialização de uma cultivar, seja ela nova ou não. Esse registro não é sinônimo de proteção de nova cultivar. Para ser concedida a proteção, certos requisitos devem ser atendidos: novidade temporal, distinguibilidade, estabilidade, homogeneidade, denominação própria e ser passível de utilização no complexo agroflorestal. A cultivar deve ser nova, um critério temporal, pois se considera novo o que não foi oferecido à venda em um período de tempo. Esse período é estabelecido na lei como inferior a doze meses da data do pedido no Brasil, em um prazo de seis anos para espécies de árvores e videiras e de quatro anos para as outras espécies para a disposição à venda em outros países..$^{58}$

A distinguibilidade refere-se à margem mínima de descritores. Descritores são as características morfológicas, fisiológicas, bioquímicas ou moleculares que são herdadas, geneticamente, e utilizadas na identificação de cultivar (fenótipo). Ser distinta de qualquer outra até a data do pedido, novamente, é um critério objetivo-temporal, ou seja, distinguir-se das cultivares já existentes. ${ }^{59}$

\footnotetext{
${ }^{57}$ Artigo 9o da Lei 9.456/97.

${ }^{58}$ Artigo 3ㅇ, inciso V, da Lei 9.456/97.

${ }^{59} \mathrm{BRUCH}$; VIEIRA; DEWES, 2015, p. 11.
} 
Art. 3ㅇ, VI - cultivar distinta: a cultivar que se distingue claramente de qualquer outra cuja existência na data do pedido de proteção seja reconhecida. (BRASIL, 1997, n.p.).

Uma cultivar estável mantém a sua homogeneidade por meio de gerações sucessivas, quando produzida em escala comercial, das suas características ou descritores (art. 3ำ, inciso VIII). Ser homogênea significa que, ao ser utilizada em plantio de escala comercial, essa cultivar mantém suas características, apresentando uma variabilidade mínima desses descritores. ${ }^{60}$

A garantia da manutenção do direito de exclusividade advém da manutenção da estabilidade dos descritores ao longo das gerações. Entretanto, no momento em que as características perderem a estabilidade, a cultivar deixa de ser protegida e passa a não ser mais possível identificar uma cultivar que foi objeto de proteção. ${ }^{61}$

Outro critério de concessão diz respeito a ser passível de utilização no complexo agroflorestal:

Art. 3으, XVIII - complexo agroflorestal: o conjunto de atividades relativas ao cultivo de gêneros e espécies vegetais visando, entre outras, à alimentação humana ou animal, à produção de combustíveis, óleos, corantes, fibras e demais insumos para fins industrial, medicinal, florestal e ornamental. (BRASIL, 1997, n.p.).

O último critério de concessão diz respeito à denominação própria da cultivar. $O$ critério do nome da cultivar lhe confere uma denominação genérica para fins de proteção. A cultivar deve, obrigatoriamente, possuir uma denominação única que não pode ser composta só por números, diferente de uma preexistente, além de não induzir ao erro quanto às suas características intrínsecas ou à sua procedência.

A proteção de novas cultivares difere do Registro de Cultivares. O registro também é realizado no MAPA, mas ele independe do direito de exclusividade. Seu objetivo é habilitar a multiplicação e a comercialização de mudas e sementes. Existem hipóteses de produção e comercialização das cultivares sem o pagamento de royalties por não estarem protegidas ou por já terem entrado

\footnotetext{
${ }^{60}$ Artigo 3으, inciso VII, da Lei 9.456/97.

${ }^{61}$ BRUCH; VIEIRA; DEWES, 2015, p. 13.
} 
em domínio público. $\mathrm{O}$ registro tem por finalidade constituir um banco de informações agronômicas, fornecendo dados ao poder público referentes à origem do material e ao seu responsável no Brasil. A finalidade da proteção refere-se ao direito de exclusividade do titular sobre o uso da cultivar. ${ }^{62}$

A proteção conferida recai sobre o material de reprodução ou de multiplicação vegetativa da planta inteira. Para tanto, faz-se um relatório descritivo mediante preenchimento de todos os descritores exigidos, uma declaração garantindo a existência da amostra viva à disposição do órgão competente e sua localização para eventual exame. ${ }^{63}$

O pedido de proteção de nova cultivar poderá se referir a uma única cultivar. Além do requerimento, o pedido deve conter os requisitos dispostos no artigo 14 da lei relativa às cultivares. Todos os documentos devem ser apresentados em língua portuguesa.

A expedição do Certificado de Proteção de Cultivar dar-se-á de forma imediata, depois de decorrido o prazo para recurso ou, se esse interposto, após a publicação oficial de sua decisão. Se aprovado o pedido e não havendo recurso tempestivo, a publicação efetuar-se-á no prazo de até quinze dias. A proteção concedida será divulgada por meio de publicação oficial, em até quinze dias, a partir da data de sua concessão. 0 artigo 22 dispõe sobre a necessidade de manter uma amostra viva da cultivar protegida à disposição do órgão competente, durante o período de proteção, assim que obtido o Certificado Provisório ou o Certificado de Proteção de Cultivar. Além disso, o titular deve enviar ao MAPA duas amostras vivas da cultivar protegida, uma para manipulação e exame, outra para integrar a coleção de germoplasma. ${ }^{64}$

Ao protocolizar o pedido, procede-se uma verificação formal preliminar quanto à existência de sinonímia cultivar e de que não haja colidência da denominação da cultivar com marcas registradas. Realiza-se um exame para verificar se o pedido de proteção está de acordo com as prescrições legais, se está tecnicamente bem definido e se não há anterioridade, ainda que com denominação diferente.

\footnotetext{
${ }^{62}$ BRUCH; VIEIRA; DEWES, 2015, p. 8.

${ }^{63}$ Artigo 14, inciso V, da Lei 9.456/97 (Lei de Cultivares).

${ }^{64}$ Entende-se como Germoplasma o material que constitui a base física da herança transmitida de uma geração para outra. Significa a matéria onde se encontra um princípio que pode crescer e se desenvolver, sendo definido, ainda, como a soma total dos materiais hereditários de uma espécie. Disponível em: <https://www.embrapa.br/recursos-geneticos-e-biotecnologia/pesquisa-e-desenvolvimento/intercambio-de-germoplasma>. Acesso em: 22 ago. 2016.
} 
O exame refere-se aos descritores, com o objetivo de confirmar a não existência de uma planta similar anteriormente, tratando da sua distinguibilidade. Assim, difere do exame de mérito das patentes e desenhos industriais, que tratam, no primeiro caso, da efetiva necessidade de algo novo, com atividade inventiva e aplicação industrial e, no segundo, da novidade e da originalidade. O que deve ser considerado na análise de uma nova cultivar é a existência de uma margem mínima de descritores - não importa se melhores ou piores que os anteriores - e que estes sejam homogêneos e estáveis nas gerações futuras.

No caso da patente de invenção, é importante que esta resolva um problema de uma área técnica específica. $O$ desenho industrial busca proteger o que é novo e original em termos estéticos, não em termos funcionais. A proteção de novas cultivares protege somente espécies vegetais que possuem os elementos mencionados anteriormente. Importante lembrar que não são passíveis de proteção as espécies não vegetais, espécies vegetais ainda não descritas e espécies vegetais que não se enquadrem no complexo agroflorestal.

Confere-se ao titular da proteção a propriedade sobre a cultivar por um período de 15 (quinze) anos a partir da data da concessão do Certificado Provisório de Proteção, excetuadas as videiras, as árvores frutíferas, as árvores florestais e as árvores ornamentais, inclusive, em cada caso, o seu porta-enxerto, para as quais a duração será de 18 (dezoito) anos. Conserva-se a proteção com o pagamento de retribuições anuais. Com o término da vigência da proteção, essa não poderá ser prorrogada, e a cultivar cairá em domínio público. A lei ainda ressalva que nenhum outro direito poderá impedir a sua livre utilização.

O Certificado de Proteção de Cultivar confere ao titular o direito à reprodução comercial no território brasileiro, ficando vedados a terceiros, durante o prazo de proteção, a produção com fins comerciais, o oferecimento à venda ou a comercialização do material de propagação da cultivar sem sua autorização. Mas a lei impõe certos limites ao direito de propriedade sobre a cultivar, ${ }^{65}$ como os atos de utilização da cultivar protegida para uso próprio, uso ou venda como alimento ou matéria-prima para produto obtido do seu plantio, melhoramento genético ou pesquisa científica ou utilização pelo pequeno produtor rural. ${ }^{66}$

A Lei de Proteção de Cultivares, em seu capítulo IV, estabelece sanções àqueles que ofenderem o direito de propriedade do titular. Note-se que apesar de tipificar as condutas, não estabelece penas para elas:

\footnotetext{
${ }^{65}$ Artigo 10 음 da Lei 9.456/97.

${ }^{66}$ Art. 10 o, inciso IV, da Lei 9.456/97.
} 
Art. 37. Aquele que vender, oferecer à venda, reproduzir, importar, exportar, bem como embalar ou armazenar para esses fins, ou ceder a qualquer título, material de propagação de cultivar protegida, com denominação correta ou com outra, sem autorização do titular, fica obrigado a indenizá-lo, em valores a serem determinados em regulamento, além de ter o material apreendido, assim como pagará multa equivalente a vinte por cento do valor comercial do material apreendido, incorrendo, ainda, em crime de violação dos direitos do melhorista, sem prejuízo das demais sanções penais cabíveis.

$\S 1$ 을 Havendo reincidência quanto ao mesmo ou outro material, será duplicado o percentual da multa em relação à aplicada na última punição, sem prejuízo das demais sanções cabíveis.

$\S 2$ ㅇ O órgão competente destinará gratuitamente o material apreendido - se de adequada qualidade - para distribuição, como semente para plantio, a agricultores assentados em programas de Reforma Agrária ou em áreas onde se desenvolvam programas públicos de apoio à agricultura familiar, vedada sua comercialização.

$\S 3$ 으 O disposto no caput e no $\S 1$ 을 deste artigo não se aplica aos casos previstos no art. 10. (BRASIL, 1997, n.p.).

\title{
TOPOGRAFIA DE CIRCUITOS INTEGRADOS
}

\begin{abstract}
A topografia de circuito integrado trata-se de um registro de um circuito integrado. A proteção é regida pela Lei $n^{\circ} 11.484$, cuja matéria já estava prevista pelo acordo TRIPS, mas só veio a virar concretamente lei em 31 de maio de 2007. Define-se circuito integrado e topografia de circuito integrado como:
\end{abstract}

Art. 26. Para os fins deste Capítulo, adotam-se as seguintes definições:

I - circuito integrado significa um produto, em forma final ou intermediária, com elementos dos quais pelo menos um seja ativo e com algumas ou todas as interconexões integralmente formadas sobre uma peça de material ou em seu interior e cuja finalidade seja desempenhar uma função eletrônica;

II - topografia de circuitos integrados significa uma série de imagens relacionadas, construídas ou codificadas sob qualquer meio ou forma, que represente a configuração tridimensional das camadas que compõem um circuito integrado, e na qual cada imagem represente, no todo ou em parte, a disposição geométrica ou arranjos da superfície do circuito integrado em qualquer estágio de sua concepção ou manufatura. (BRASIL, 2007, n.p.). 
Denis Borges Barbosa (2010, p. 2144) conceitua o circuito integrado como:

\begin{abstract}
Um circuito integrado (o microship) é um pequeno aparelho com circuito eletroeletrônico completo (funcionando como transistores, resistências e suas interconexões) fabricado em peça de material semicondutor, como o silício, germânio ou arsenídio de gálio, folheados em wafers de 8 ou 12 camadas. Alguns circuitos integrados são usados como memória (as RAMs, ROMs, EPROMs); outros são utilizados como processadores, realizando funções lógicas e matemáticas em computador.
\end{abstract}

O registro da topografia, por meio da proteção de ativo intangível denominado topografia de circuito integrado, no INPI é o que confere a proteção, independentemente da fixação da topografia. Diferentemente da patente, não há a ideia de troca do direito de exclusividade pela divulgação da tecnologia, assim não há uma publicação da topografia de forma a torná-la de acesso público. ${ }^{67}$

Confere-se a proteção somente às topografias que forem originais, resultantes de esforço intelectual de seu criador ou criadores e que não sejam comuns ou vulgares para técnicos especialistas ou fabricantes de circuitos integrados no momento de sua criação. Originais no sentido de sistematização, organização e disponibilização dos elementos do conjunto de forma criativa e também na concepção de distinguível. ${ }^{68}$

O registro protege o caminho pelo qual a informação passa dentro do circuito, ou seja, a forma da topografia. O direito recai sobre uma única topografia, mais especificamente a configuração tridimensional das camadas que a compõem. ${ }^{69}$

O pedido do registro pode recair sobre uma única topografia e deve conter a sua descrição e a sua correspondente função, além de desenhos ou fotografias da topografia, que são essenciais para permitir sua identificação e caracterizar sua originalidade. Também devem estar presentes o requerimento, a declaração de exploração anterior, se houver, indicando a data de seu início e o comprovante do pagamento da retribuição relativa ao depósito do pedido de registro. Requer-se que os documentos estejam em língua portuguesa. $O$ processamento do pedido segue o disposto nos artigos 33 e 34 da Lei $n^{\circ} 11.484 / 2007$.

\footnotetext{
${ }^{67}$ BARBOSA, 2010, p. 2173.

68 Ibidem, p. 2166.

${ }^{69}$ Artigo 26, inciso II, da Lei $n^{\circ} 11.484 / 07$.
} 
Art. 33. Protocolizado o pedido de registro, o INPI fará exame formal, podendo formular exigências as quais deverão ser cumpridas integralmente no prazo de 60 (sessenta) dias, sob pena de arquivamento definitivo do pedido.

Parágrafo único. Será também definitivamente arquivado o pedido que indicar uma data de início de exploração anterior a 2 (dois) anos da data do depósito.

Art. 34. Não havendo exigências ou sendo elas cumpridas integralmente, o INPI concederá o registro, publicando-o na íntegra e expedindo o respectivo certificado.

Parágrafo único. Do certificado de registro deverão constar o número e a data do registro, o nome, a nacionalidade e o domicílio do titular, a data de início de exploração, se houver, ou do depósito do pedido de registro e o título da topografia. (BRASIL, 2007 , n.p.).

A topografia de circuito integrado, diferentemente das patentes, não necessita de um exame de mérito, atendidas às condições do artigo 31 da Lei 11.484/07 para o pedido de registro, o qual segue o protocolo.

O sigilo do pedido é opcional, ele pode ser requerido pelo depositante do pedido. Possui duração de 6 (seis) meses, contados a partir da data do depósito. Durante esse período, há a possibilidade de retirada do pedido com a devolução da documentação ao interessado, sem produção de qualquer efeito, desde que o requerimento seja apresentado ao INPI até 1 (um) mês antes do fim do prazo de sigilo.

A proteção da topografia não engloba conceitos, processos, sistemas ou técnicas nos quais a topografia se baseie ou qualquer informação armazenada pelo emprego da referida proteção. Protegem-se aquelas topografias que tiverem os requisitos já mencionados, como também as topografias que resultem de uma combinação de elementos e interconexões comuns ou que incorporem, com a devida autorização, topografias protegidas de terceiros. Tutela-se a combinação, considerada como um todo, que atender à originalidade, no sentido de que resulte do esforço intelectual do seu criador ou criadores e que não seja comum ou vulgar para técnicos, especialistas ou fabricantes de circuitos integrados no momento de sua criação. Assim, depreende-se a possibilidade de topografias baseadas nos conceitos, técnicas ou elementos incorporados em topografia preexistente, desde que a topografia derivada constitua criação nova em razão do critério de originalidade ${ }^{70}$.

\footnotetext{
${ }^{70}$ SANTOS; JABUR, 2007, p. 265.
} 
O período de proteção da topografia é de 10 (dez) anos, os quais começam a contar a partir da data do depósito ou da primeira exploração. Não existe a possibilidade de renovação da proteção.

O titular da topografia de circuito integrado pode explorar com exclusividade a topografia e impedir que terceiros reproduzam, importem, vendam ou distribuam por outro modo, para fins comerciais, uma topografia protegida ou produto, além de obter indenização pela exploração indevida de seu objeto. 0 artigo 54 da lei referente às topografias define sanções para quem infringir a proteção.

Art. 54. Comete crime de violação de direito do titular de topografia de circuito integrado quem, sem sua autorização, praticar ato previsto no art. 36 desta Lei, ressalvado o disposto no art. 37 desta Lei.

§ 10 Se a violação consistir na reprodução, importação, venda, manutenção em estoque ou distribuição, para fins comerciais, de topografia protegida ou de circuito integrado que a incorpore:

Pena: detenção, de 1 (um) a 4 (quatro) anos, e multa.

§ 2ㅇ A pena de detenção será acrescida de $1 / 3$ (um terço) à $1 / 2$ (metade) se:

I - o agente for ou tiver sido representante, mandatário, preposto, sócio ou empregado do titular do registro ou, ainda, do seu licenciado; ou

II - o agente incorrer em reincidência.

§ 3ㅇ O valor das multas, bem como sua atualização ou majoração, será regido pela sistemática do Decreto-Lei $\mathrm{n}^{\circ} 2.848$, de 7 de dezembro de 1940 - Código Penal.

$\S 4$ ㅇ Nos crimes previstos neste artigo somente se procede mediante queixa, salvo quando praticados em prejuízo de entidade de direito público, empresa pública, sociedade de economia mista ou fundação instituída pelo poder público.

$\S 5$ o Independentemente da ação penal, o prejudicado poderá intentar ação para proibir ao infrator a prática do ato incriminado, com a cominação de pena pecuniária para o caso de transgressão do preceito, cumulada de perdas e danos. (BRASIL, 2007, n.p.).

A lei estabelece limites legais aos direitos do titular da topografia, sendo eles os atos de análise, avaliação, ensino e pesquisa, os que consistam na criação ou exploração de uma topografia que resulte da análise, avaliação e pesquisa de topografia protegida, as topografias colocadas em circulação pelo seu 
titular ou com o consentimento dele. Os atos de terceiro que não sabia, ou não tinha como saber, que o produto ou o circuito integrado incorporava uma topografia protegida reproduzida ilicitamente, não interferem no direito do titular. ${ }^{71}$

Entretanto, estabelece-se que depois de notificado o responsável pelos atos ou por sua determinação, poderá efetuar tais atos com relação aos produtos ou circuitos integrados em estoque ou previamente encomendados, desde que, com relação a esses produtos ou circuitos, pague ao titular do direito a remuneração equivalente à que seria paga no caso de uma licença voluntária.

\section{EXEMPLOS DE DUPLA PROTEÇÃO}

A partir da distinção entre as formas de proteção de ativos intangíveis, percebe-se que a maior diferenciação entre os institutos analisados é que a patente protege a função, enquanto os outros a forma. Assim como há uma proteção diferenciada, questiona-se a possibilidade de proteger um mesmo objeto por mais de um instituto. O Brasil, como será demonstrado, possui invenções passíveis de dupla proteção, bem como decisões que reconhecem essa possibilidade.

\section{Dupla Proteção de Patente de Invenção e Desenho}

\section{Industrial}

A proteção sob duas formas distintas de tutelas da propriedade industrial pode ser verificada em uma impressora que é protegida por meio de patente de invenção pertencente à empresa Hewlett-Packard Company (HP). Também há proteção à forma dos cartuchos de impressão da impressora patenteada por meio de desenho industrial. Dessa forma, não só a impressora não pode ser reproduzida sem o consentimento dos titulares, como também, ao terminar o período de proteção da patente, não será possível reproduzi-la sem que se tenha o licenciamento para utilizar o formato dos cartuchos durante o prazo de vigência do registro de desenho industrial.

\footnotetext{
${ }^{71}$ Artigo 37, inciso IV, da Lei 11.484/07.
} 
Figura 1 - Impressora de Jato de Tinta Modular

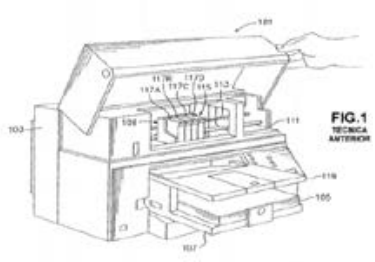

№ do pedido: PI 9908943-2 A2

Data do Depósito: 12/03/1999

Título: IMPRESSORA DE JATO DE TINTA

MODULAR

Nome do Depositante: Hewlett-Packard

Company (US)

Nome do Inventor: James P. Axtell / Trudy L.

Benjamin / David J. Lowe / Preston D. Seu / Blair

M. Kent

Fonte: Imagem retirada do pedido de patente de invenção $\mathrm{n}^{\circ}$ PI 9908943-2 A2. Disponível no INPI.
Figura 2 - Configuração Aplicada em

Cartucho de Tinta
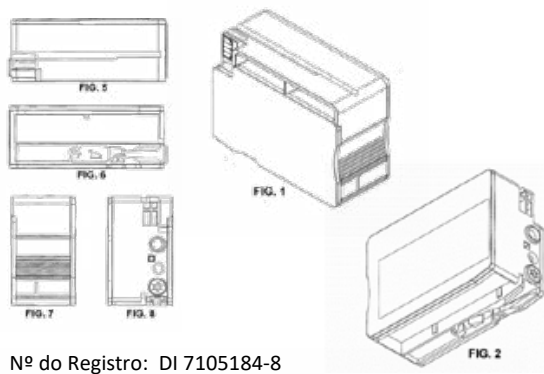

№ do Registro: DI 7105184-8

Data do Depósito: 30/09/2011

Título: CONFIGURAÇÃO APLICADA EM CARTUCHO DE

TINTA

Nome do Titular: HEWLETT-PACKARD DEVELOPMENT

COMPANY L.P. (US)

Nome do Autor: DAVID C. HARVEY / RALPH L. STATHEM

/ DAVID N. OLSE

Fonte: Imagem retirada do pedido de registro de desenho industrial $\mathrm{n}^{\circ}$ DI 7105184-8. Disponível no INPI.

\section{Dupla Proteção de Patente de Invenção e Nova Cultivar}

Em relação à proteção de novas cultivares, há precedente do Tribunal de Justiça do Rio Grande do Sul em que a Relatora do acórdão, Dra. Maria Cláudia Mércio Cachapuz, identifica as sutilezas entre a proteção da patente e as da cultivar, não negando que coexistam sobre um mesmo objeto.

APELAÇÃO CÍVEL. AÇÃO COLETIVA. DIREITO À PROPRIEDADE INTELECTUAL. SOJA TRANSGÊNCIA. LEI DE PATENTES E LEI DE PROTEÇÃO DE CULTIVARES. RAZÕES DE AGRAVOS RETIDOS AFASTADAS E PRELIMINARES SUPERADAS. Suficiência do laudo pericial e ausência de nulidade da prova a afastar o acolhimento das razões dos agravos retidos. Preliminares superadas por julgamento no STJ. Afastamento da disciplina normativa do Código de Defesa do Consumidor, não aplicada ao caso em discussão nos autos. No mérito, ainda que a Lei de Patentes não permita a proteção decorrente de patentes para o todo ou partes de seres vivos, houve expressa exclusão desta proibição em relação aos microorganismos transgênicos (art. 18, inc. III, da Lei de Patentes), justamente porque resultantes de um produto de intervenção cultural, por meio do invento. Possível a extensão 
dos efeitos da propriedade intelectual sobre microorganismos transgênicos desde que atendam aos critérios próprios à situação jurídica de patenteabilidade - no caso, a novidade, a atividade inventiva e a aplicabilidade à atividade industrial. Circunstância expressamente reconhecida, por certificados próprios, em relação ao produto ora discutido em juízo. Não há como excluir dos efeitos de proteção desta o produto do objeto de patente, por força da proteção conferida pelo art. 42 da Lei no 9.279/96. A doutrina, na interpretação mais correta da Lei de Patentes acerca de casos de propriedade intelectual, esclarece que o art. 42 da Lei 9.279/96, por meio de seus incisos, protege tanto o produto que é objeto direto da patente, como o processo ou o produto obtido diretamente pelo processo, caso seja este patenteado. Descabe excluir-se o direito de patentes sobre o produto de uma intervenção humana por técnica de transgenia - e que abranja todas as características próprias à proteção -, inclusive quando isto ocorra sobre uma cultivar. $\mathrm{E}$ isto, porque ambas as Leis mencionadas são omissas na hipótese de sobreposição de situações. Quando uma variedade é desenvolvida pela técnica da transgenia - podendo, portanto, receber a proteção da Lei de Patentes - e sofre, posteriormente, uma melhora por via biológica, recebendo o certificado de cultivares, em tese, tem-se situação de duplicidade de proteção, algo que estaria vedado pelas disposições da UPOV referente à Convenção de 1978. Tal conflito, para a doutrina mais recente, enquanto inexistente uma definição legal específica, poderia sofrer solução suficiente por meio do instituto da "patente dependente", previsto na disciplina da Lei de Patentes. Não se trata, portanto, de hipótese de aplicação de lei mais específica, para a resolução do conflito de regras. Aqui, tem-se leis que disciplinam objetos de tutela diversos. A própria Exposição de Motivos da cartilha elaborada à Lei no 9.456/97 deixa clara tal situação quando justifica a criação da Lei de Proteção de Cultivares como "mecanismo distinto de proteção à prop... há como fazer subsistir o argumento de que o licenciamento concedido para a pesquisa sobre o produto e para o desenvolvimento de técnica de aperfeiçoamento afaste o direito originário sobre patentes. O que pode é o titular de patente celebrar contrato de licença para exploração e investir o licenciado nos poderes para agir em defesa da patente (art. 61 da Lei de Patentes). Tal não afasta os direitos de exercício desta titularidade, seja pelo proprietário do invento, seja pelo licenciado, ressalvada apenas a hipótese de análise do aperfeiçoamento introduzido em patente licenciada (art. 63 da Lei de Patentes). O debate proposto é referente ao produto da soja transgênica, para a qual é identificada a situação de proteção específica e comprovada - ao menos até 31.08.2010 - por meio de carta de patente. Não há, portanto, como se pretender a aplicação de disposições normativas da Lei de Proteção de Cultivares para o caso em comento, na medida em que diversa é a proteção jurídica identificada. Reconhece-se causa legítima à cobrança - a descaracterizar 
hipótese de ilicitude para os fins do art. 187 do CC brasileiro -, por força de aplicação da Lei de Patentes na hipótese, não afastada a cobrança por situação diversa de proteção do produto pela Lei de Cultivares, como na hipótese das exceções do art. 10 da Lei referida. Com relação ao percentual de royalties estabelecido, a desproporção é apontada ainda na inicial, por meio de "seja judicialmente estabelecido percentual não abusivo para adequadamente indenizar as demandadas, em índices que variam entre $0,06 \%$ a $0,10 \%$ sobre o valor da soja transgênica comercializada, preferindo o menor índice pelas razões anotadas" (fl. 31 dos autos). Nesse ponto, há que se observar os limites estabelecidos em Lei e mesmo a partir de acordos mais amplos, realizados entre os envolvidos, por meio de suas entidades representantivas. Não há que se falar em abusividade quando negociados entre entidades representantes de ambas as partes royalties em percentual (2\%) proporcional à prática de mercado internacional, sem que demonstrada efetiva abusividade de cobrança. Sucumbência invertida e honorários advocatícios redimensionados em concreto. À UNANIMIDADE, DESACOLHERAM OS AGRAVOS RETIDOS E AFASTARAM AS PRELIMINARES. NO MÉRITO, POR MAIORIA, DERAM PROVIMENTO AO RECURSO, VENCIDO O DESEMBARGADOR JORGE LUIZ LOPES DO CANTO. (Apelação Cível no 70049447253, Quinta Câmara Cível - Serviço de Apoio Jurisdição, Tribunal de Justiça do RS, Relator: Maria Claudia Cachapuz, Julgado em 24/09/2014).

No decorrer do seu voto, a Relatora diferencia sucintamente as patentes da proteção de cultivares, bem como reconhece que o ordenamento pátrio não deixa claro a possibilidade de dupla proteção, conforme os seguintes trechos da decisão:

Bem analisada a matéria em discussão, a própria doutrina mencionada na sentença de 10 grau refere que as Leis $\mathrm{n}$ 0 9.279/96 (Lei de Patentes) e 9.456/97 (Lei de Proteção de Cultivares) são distintas entre si e, na abrangência, não se confundem quanto à proteção de seu objeto. Ainda que a Lei de Patentes não permita a proteção decorrente de patentes para o todo ou partes de seres vivos, houve expressa exclusão desta proibição em relação aos microorganismos transgênicos (art. 18, inc. III, da Lei de Patentes), justamente porque resultantes de um produto de intervenção cultural, por meio do invento.

Isto representa afirmar que é possível a extensão dos efeitos da propriedade intelectual sobre microorganismos transgênicos desde que atendam aos critérios próprios à situação jurídica de patenteabilidade - no caso, a novidade, a atividade inventiva e a aplicabilidade à atividade industrial. Circunstância expressamente reconhecida, por certificados próprios, em relação ao produto ora discutido em juízo. 
Quando uma variedade é desenvolvida pela técnica da transgenia - podendo, portanto, receber a proteção da Lei de $\mathrm{Pa}-$ tentes - e sofre, posteriormente, uma melhora por via biológica, recebendo o certificado de cultivares, em tese, tem-se situação de duplicidade de proteção, algo que estaria vedado pelas disposições da UPOV referente à Convenção de 1978. Tal conflito, para a doutrina mais recente, enquanto inexistente uma definição legal específica, poderia sofrer solução suficiente por meio do instituto da "patente dependente", previsto na disciplina da Lei de Patentes, como em destaque:

[...]

Não se trata, portanto, de hipótese de aplicação de lei mais específica, para a resolução do conflito de regras. Aqui, tem-se leis que disciplinam objetos de tutela diversos. A própria Exposição de Motivos da cartilha elaborada à Lei no 9.456/97 deixa clara tal situação quando justifica a criação da Lei de Proteção de Cultivares como "mecanismo distinto de proteção à propriedade intelectual." E é a justificação da Lei de Proteção de Cultivares que oferece a finalidade específica de criação de norma complementar de proteção: "Isso permitirá uma negociação equilibrada entre aqueles que investiram maciçamente na obtenção de variedades adaptadas às condições ecológicas do Brasil e aqueles detentores de patentes de processos biotecnológicos e de genes, quando do desenvolvimento de cultivares transgênicos".

Com a criação da lei mais recente (Lei de Proteção de Cultivares), há nítida pretensão de favorecimento à pesquisa nacional sobre produtos modificados com a criação da Lei, não para afastar os direitos de propriedade sobre quem detenha a patente, e sim para reservar, sobre o produto modificado (o cultivar) o direito de propriedade sobre o bem que sofre variação na sua composição.

Nos casos de microorganismos transgênicos, tal não afasta, por conseqüência, a possibilidade de cobrança de royalties a quem detém a propriedade sobre o invento em relação à comercialização futura do produto. Seja pela proteção originária e clássica da Lei de Patentes, quando existente apenas o reconhecimento da patente originária; seja pela proteção subsequente de cultivar, por modificação sobre o vegetal - quando caracterizada tal situação com certificação própria reconhecida oficialmente -, por meio da solução prevista na Lei de Patentes, e destacada pela doutrina, do instituto da patente dependente. Num ou noutro caso, contudo, não se vê afastada a possibilidade de exercício dos atributos de disposição sobre a propriedade do invento. (Apelação Cível no 70049447253, Quinta Câmara Cível - Serviço de Apoio Jurisdição, Tribunal de Justiça do RS, Relator: Maria Claudia Cachapuz, Julgado em 24/09/2014. Grifos nossos). 


\section{Dupla Proteção de Patente de Invenção e Topografias de Circuito Integrado}

Quanto às topografias de circuito integrado, uma vez que a proteção recai somente pelo caminho que a informação percorre, as outras partes do microchip, em que há proteção da topografia, podem ser protegidas por outros institutos. Denis Borges Barbosa (2010, p. 2169-2170) apresenta esta possibilidade, uma vez que as diversas proteções recairiam sobre objetos distintos:

De outro lado, pode acontecer que tais conceitos, processos, sistemas ou técnicas sejam objeto de proteção patentária, ou da lei relativa aos programas de computador; as informações armazenadas pelo emprego da mesma tutela autoral geral, ou ainda daquela específica das bases de dados. Em suma, a norma em questão, que configura proteção meramente de forma, não implica em liberdade de uso de conteúdo, mas simplesmente em exclusão da proteção registral específica.

A cumulação de proteções recai não sobre o mesmo objeto de direito, mas sobre o objeto fáctico e econômico - como uma garrafa de cerveja pode ser protegida por desenho industrial, por marca, por patente, etc., sem que isso viole o princípio constitucional geral da especificidade de proteções.

\section{CONSIDERAÇÕES FINAIS}

A partir da análise entre as formas de tutela da Propriedade Industrial, conclui-se que uma invenção pode ser protegida por mais de uma das formas de proteção de ativos intangíveis no Brasil, uma vez que esses institutos constituem diferentes métodos de tutela. Enquanto a patente protege a função, o desenho industrial, a proteção de novas cultivares e a topografia de circuitos integrados protegem a forma da criação, seja essa o conjunto de linhas e cores (desenho industrial), ou o fenótipo (novas cultivares), ou o caminho da informação (topografia de circuitos integrados).

A comparação dos institutos apresentados sumariza-se nos seguintes tópicos:

1. Desenho Industrial e Patente:

- Quanto ao objeto de proteção: apenas protege a configuração externa. 
- Requisito da originalidade que não está presente para as Patentes.

- Quanto ao sigilo: deve ser requerido pelo depositante.

- Quanto ao exame de mérito: não é requisito de concessão do registro, pode ser requerido a qualquer momento pelo titular.

- $\quad$ Pode ter seu registro prorrogado por 3 (três) períodos sucessivos de 5 (cinco) anos cada.

- Valor de depósito mais elevado que o da Patente.

- $\quad$ Registro de DI concedido simultaneamente com o depósito e a publicação do pedido.

2. Proteção de Novas Cultivares e Patente:

- O critério da novidade é temporal e não algo absolutamente novo como no caso da Patente.

- A Patente apenas protege a composição genética. Já a Proteção de Nova Cultivar protege o material de reprodução ou multiplicação vegetativa da planta, o fenótipo.

- $\quad$ Proteção de Nova Cultivar não possui propriamente um exame de mérito e um tempo de sigilo do pedido.

- $\quad$ A ideia de retribuição à sociedade pelo direito de exclusividade não é um destaque da Proteção de Nova Cultivar da forma como o é na Patente.

3. Topografia de Circuito Integrado e Patente:

- A Topografia de Circuito Integrado protege a forma do objeto.

- Não há publicação da topografia para torná-la de acesso público.

- $\quad$ Não exige exame de mérito, apenas o formal.

- Não depende de fixação.

- $\quad$ Sigilo opcional.

- Não necessita de uma contribuição de manutenção do registro.

- Concepção de originalidade, não de novidade, no sentido de ser distinto.

Para melhor visualizar todos os aspectos dos institutos de proteção de ativos intangíveis, bem como suas similitudes e diferenças, criou-se um quadro comparativo: 
Quadro 1 - Análise Comparativa entre os Institutos da Patente de Invenção e de Modelos de Utilidade e Formas de Proteção Correlatas: Desenho Industrial, Proteção de Novas Cultivares e Topografia de Circuitos Integrados

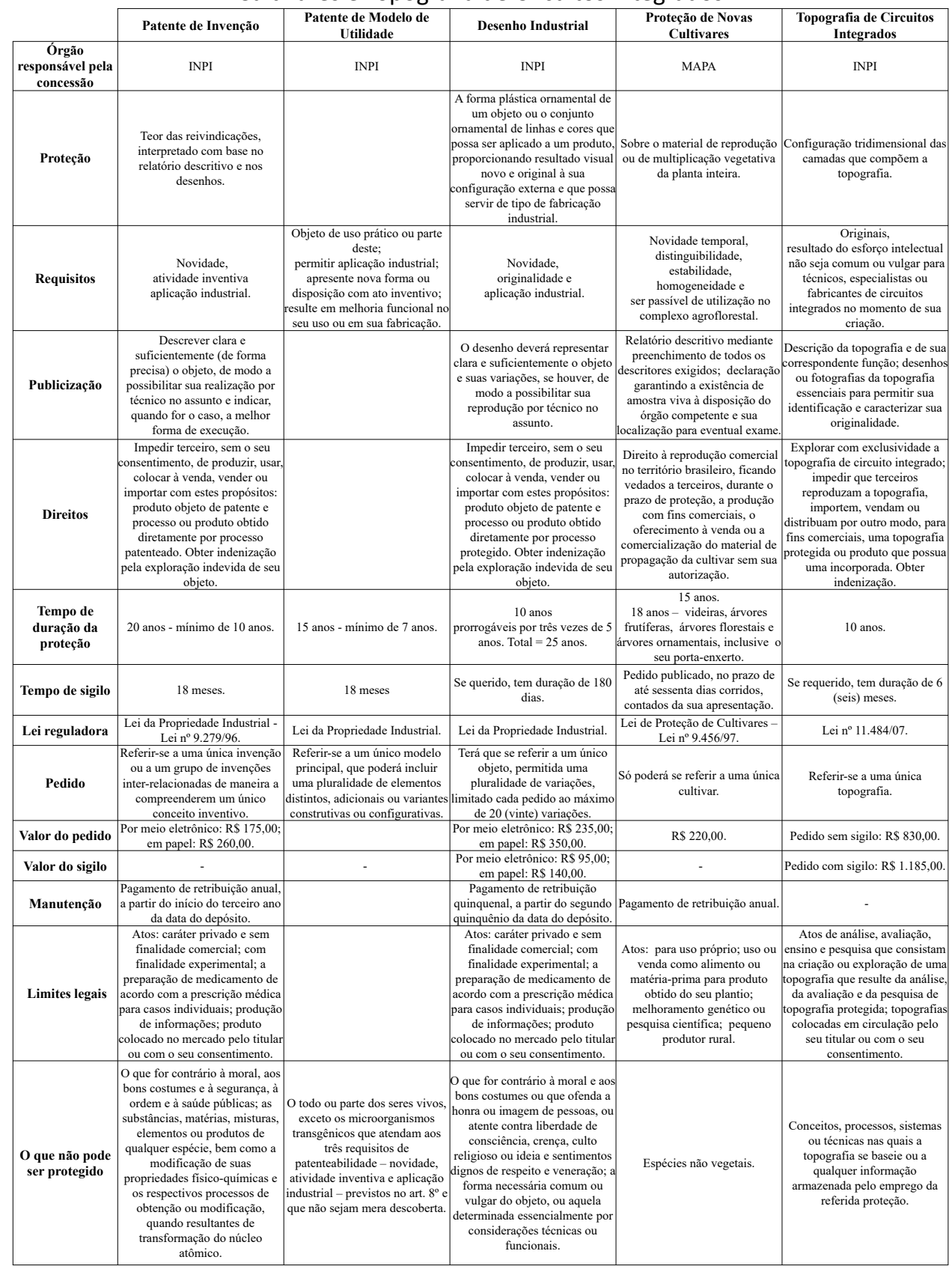

Fonte: Elaboração própria dos autores. 


\section{REFERÊNCIAS}

BARBOSA, D. B. Tratado da Propriedade Intelectual. Tomo III. Rio de Janeiro: Editora Lumen Juris, 2010.

BARCELLOS, M. L. L. O Sistema Internacional de Patentes. São Paulo: IOB Thomson, 2004.

BRASIL. Decreto-Lei no 2.848, de 7 de dezembro de 1940. Código Penal. Diário Oficial [da] República Federativa do Brasil. Brasília, DF, 31 de dezembro de 1940. Seção 1, p. 23911. Disponível em: <http://www2.camara.leg.br/ legin/fed/declei/1940-1949/decreto-lei-2848-7-dezembro-1940-412868publicacaooriginal-1-pe.html>. Acesso em: 17 maio 2016.

BRASIL. Lei no 9.279, de 14 de maio de 1996. Regula direitos e obrigações relativos à propriedade industrial. Diário Oficial [da] República Federativa do Brasil. Brasília, DF, 15 de maio de 1996. Disponível em: <http://www.planalto. gov.br/ccivil/leis/l9279.htm>. Acesso em: 17 maio 2016.

BRASIL. Lei no 9.456, de 25 de abril de 1997. Institui a Lei de Proteção de Cultivares e dá outras providências. Diário Oficial [da] República Federativa do Brasil. Brasília, DF, 8 de maio de 1997, retificada em 26 de agosto de 1997 e 25 de setembro 1997. Disponível em: <http://www.planalto.gov.br/ccivil/leis/ 19279.htm>. Acesso em: 17 maio 2016.

BRASIL. Lei no 9.609, de 19 de fevereiro de 1998. Dispõe sobre a proteção da propriedade intelectual de programa de computador, sua comercialização no País, e dá outras providências. Diário Oficial [da] República Federativa do Brasil. Brasília, DF, 20 de fevereiro de 1998, retificado em 25 de fevereiro de 1998a. Disponível em: <http://www.planalto.gov.br/ccivil_03/leis/l9609.htm>. Acesso em: 17 maio 2016.

BRASIL. Lei no 9.610, de 19 de fevereiro de 1998. Altera, atualiza e consolida a legislação sobre direitos autorais e dá outras providências. Diário Oficial [da] República Federativa do Brasil. Brasília, DF, 20 de fevereiro de 1998b. Seção 1, p. 3. Disponível em: <http://www2.camara.leg.br/legin/fed/lei/1998/lei-9610-19fevereiro-1998-365399-norma-pl.html>. Acesso em: 17 maio 2016.

BRASIL. Lei no 11.484, de 31 de maio de 2007. Dispõe sobre os incentivos às indústrias de equipamentos para TV Digital e de componentes eletrônicos semicondutores e sobre a proteção à propriedade intelectual das topografias 
de circuitos integrados, instituindo o Programa de Apoio ao Desenvolvimento Tecnológico da Indústria de Semicondutores - PADIS e o Programa de Apoio ao Desenvolvimento Tecnológico da Indústria de Equipamentos para a TV Digital PATVD; altera a Lei no 8.666, de 21 de junho de 1993; e revoga o art. 26 da Lei no 11.196, de 21 de novembro de 2005. Diário Oficial [da] República Federativa do Brasil. Brasília, DF, 31 de maio de 2007 [edição extra]. Disponível em: <http:// www.planalto.gov.br/ccivil/leis/l9279.htm>. Acesso em: 17 maio 2016.

BRUCH, K. L.; VIEIRA, A. C. P.; DEWES, H. A Propriedade Industrial: dupla proteção ou proteções coexistentes sobre uma mesma planta. In: BUAINAIN, A. M.; BONACELLI, M. B.; MENDES, C. I. C. (Eds.). Propriedade Intelectual e Inovações na Agricultura. Rio de Janeiro: Instituto Nacional de Ciência e Tecnologia/Políticas Públicas, Estratégias, 2015. [no prelo]. Disponível em: <https://www.tjrs.jus. br/export/poder_judiciario/tribunal_de_justica/centro_de_estudos/doutrina/ doc/artigo_cultivares_x_patentes.pdf>. Acesso em: 17 maio 2016.

BRUCH, K. L.; VIEIRA, A. C. P.; DEWES, H. Proteção de Cultivares e Patentes de Invenção: uma coexistência possível. PIDCC, Aracaju, v. 9, n. 03, p. 67-93, out. 2015. Disponível em: <http://pidcc.com.br/artigos/102015/03102015.pdf>. Acesso em: 17 maio 2016.

BRUCH, K. L.; ZIBETTI, F. W.; BRIGIDO, E. V. Acordos Internacionais e sua Internalização: um estudo de caso comparativo entre Brasil e China no âmbito da Propriedade Intelectual. In: MENEZES, W. (Org.). Estudos de Direito Internacional. Curitiba: Juruá, 2008, v. XII, p. 1-15.

CERQUEIRA, J. da G. Tratado da Propriedade Intelectual. Volume II, Tomo I. Rio de Janeiro: Editora Lumen Juris, 2012.

EMPRESA BRASILEIRA DE PESQUISA AGROPECUÁRIA -EMBRAPA. Intercâmbio de germoplasma. Sem data de publicação. [on-line]. Disponível em: <https://www. embrapa.br/recursos-geneticos-e-biotecnologia/pesquisa-e-desenvolvimento/ intercambio-de-germoplasma>. Acesso em: 22 ago. 2016.

INSTITUTO NACIONAL DA PROPRIDADE INTELECTUAL - INPI. Perguntas Frequentes: Patente. Última modificação: 07 de março de 2017. Disponível em: <http://www.inpi.gov.br/>. Acesso em: 17 maio 2017.

PLETSCH, L. W. Desenho Industrial: Possibilidade de Dupla Proteção. Trabalhos 2009. Porto Alegre: Pontifícia Universidade Católica do Rio Grande do Sul, 2009. 40 p. Disponível em: <http://www3.pucrs.br/pucrs/files/uni/poa/direito/ graduacao/tcc/tcc2/trabalhos2009_1/laura_pletsch.pdf>. Acesso em: 04 ago. 2016. 
SANTOS, M. J. P. dos; JABUR, W. P. Propriedade Intelectual: Contratos de propriedade Industrial e Novas Tecnologias. São Paulo: Saraiva, 2007.

TEIXEIRA, F. A. de S. Tudo o que vocês queriam saber sobre patentes mas tinha vergonha de perguntar. São Paulo: Ed. do Autor, 2006. 147 p.

TRIBUNAL DE JUSTIÇA DO RIO GRANDE DO SUL. Quinta Câmara Cível - Serviço de Apoio Jurisdição. Apelação Cível no 70049447253. Relator: Maria Claudia Cachapuz, Julgado em 24/09/2014. 